\title{
66 DIPPING PRISM MODELLING OF SUBDUCTION PLATES IN VIEW OF AN IMPROVED GOCE GLOBAL MOHO: THE TONGA EXAMPLE,
}

\author{
Ahmed Hamdi Mansi* ${ }^{*}, 1,2$, Daniele Sampietro ${ }^{3}$, Mirko Reguzzoni ${ }^{4}$, Lorenzo Rossi ${ }^{4}$ \\ (1) Civil Engineering Department, College of Engineering, Shaqra University, Dawadmi, Ar Riyadh, Saudi Arabia \\ (2) Istituto Nazionale di Geofisica e Vulcanologia, sezione di Pisa, Pisa (PI), Italy \\ (3) Geomatics Research \& Development s.r.l., Lomazzo (CO), Italy \\ ${ }^{(4)}$ Department of Civil and Environmental Engineering, Politecnico di Milano, Milan (MI), Italy
}

Article history

Receveid February 6, 2018; accepted November 30, 2018.

Subject classification:

Magnetospheric GOCE, Gravity Gradients, Kermadec-Tonga subduction, Simulated Annealing, Kriging.

\begin{abstract}
The study of subduction zones, i.e. the process occurring at convergent boundaries by which one tectonic plate moves under another and sinks into the mantle, is a fundamental topic in many Earth-related sciences. Since usually important density variations occur in the correspondence of subduction zones, a proper modelling of these regions is fundamental when studying the Earth crust from gravity field observations. In the present work, we investigate the possibility to characterize a subduction zone by exploiting GOCE gravity gradients. The main objective of the work is to find a simple way to model subducting plates in view of a global inversion of the gravity field to recover the main features of the Earth crust. In particular, GOCE along-orbit filtered data are firstly reduced for the effects of the bathymetry, upper-sediments, middle-sediments, and lower-sediments. After that, the residual signal is further reduced for the effect of a "regular crust" by means of a Kriging procedure, isolating, in this way, the gravitational effect of the subducting plate. The signal is thus fitted, by means of a simulated annealing (SA) procedure, with the gravitational effect of a dipping prism, characterized by a set of parameters that define the prism position, size, density, and its strike and dipping angles.

The methodology has been firstly assessed in a closed-loop experiment to test the performance of the SA algorithm in detecting the parameters used to best fit the isolated gravitational signal of the subduction plate. Then, the Tonga subduction plate has been chosen as a natural laboratory to perform some numerical experiments. The closed-loop simulations have shown the capability of the proposed approach to estimate the parameters with a relative error smaller than 10\%, even in the presence of observation noise. As for the Tonga subduction, the estimated model well-fit the observed gravitational signal and its geometric parameters are highly-consistent with the values available in the literature.
\end{abstract}

\section{INTRODUCTION}

The study of the main subduction plates is usually performed by combining several different methodologies and observations: high accuracy mapping of seismicity [Engdahl et al., 1998; Deal et al., 1999, and updates] and moment tensor catalogues (gCMT, http://www.globalcmt.org) can, for instance, give direct information about the Benioff-Wadati zone (i.e. the boundary between the subducting oceanic lithosphere beneath either a continental lithosphere or another oceanic lithosphere), while active-source seismic data allow constraining the shallow section of the subducting slabs in a similar way. The incorporation of deep seismicity (where all earthquakes occur within subducted slabs, regardless of the mechanism) offers the possibility to improve the modelling by introducing a possible curvature of subducting slabs occurring over their descend into the mantle [England et al., 2004; Syracuse and Abers, 2006]. Finally, the availability of 
high-resolution bathymetry and sediment layers can help in defining the geometry of the slab at the trenches. One of the most complete products generated by these kinds of studies is the Slab1.0 model [Hayes et al., 2012], which is a global model that describes the three-dimensional geometry of the main subduction zones obtained by compiling and exploiting many subduction-related seismic data.

Since there is, generally, a large mass density discontinuity in correspondence with subducting plates, due to the presence of a net separation between the lighter crustal and the heavier mantle masses, gravity data can be used to study subduction zones. For instance, ground gravity data, i.e. Bouguer anomalies, were used to study the crustal thickness and the subducting lithosphere in Greece showing a good agreement with the recent seismological results [Tsokas and Hansen, 1997], while gravity field models derived from the GEOdetic SATellite (GEOSAT), SEAfaring SATellite (SEASAT), and European Remote-Sensing (ERS-1) satellite altimetry data were combined with multichannel seismic records and shipborne gravity data to study the South East Pacific-Antarctic region, leading to a model of converging oceanic crustal blocks with a partial subduction in the Bellingshausen Sea [Gohl et al., 1997].

The use of gravity observations in such a kind of studies has been up to now quite limited due to the specific geometry of the problem. In fact, subduction plates usually extend in large areas, thus requiring long and expensive airborne gravity campaigns. Even more, the significant depth of the slabs, which can reach several hundreds of kilometres, makes the characterization of subducting plates a difficult task. With the advent of the European Space Agency (ESA) mission GOCE (Gravity field and steady-state Ocean Circulation Explorer) [Drinkwater et al., 2003], new important information can be added to improve the problem solution. Actually, several studies have already shown the capabilities of GOCE data to retrieve Solid Earth information, see for instance [Bagherbandi et al., 2013; Sampietro et al., 2014; Eshagh et al., 2016; Barzaghi et al., 2016; Ye et al., 2016; Abrehdary et al., 2017; Tondi et al., 2017; Sampietro et al., 2018-b; Sobh et al., 2018-a; Sobh et al., 2018-b; Reguzzoni et al., 2019] and in particular to infer the mantle mass density distribution. For the latter topic, see Bouman et al. [2015], where GOCE gravity gradients have been used to determine the structure of the crust and the upper mantle in the North East Atlantic region and in Saudi Arabia, or Panet et al. [2014], where global anomaly grids of the Earth's gravitational gradients at satellite altitude have been used to study the geometry of the mantle masses down to mid-mantle depths.

While looking at GOCE grids of gravity gradients at satellite altitude, a very high-frequency spatial component characterized by a large amplitude can be observed on the diagonal components of the Marussi tensor over subduction zones, thus leading from the one hand to the inquiry about the capability of using GOCE to study and map these regions (see Figure 1), and on the other hand to the necessity of modelling these regions, even in a simplified way, when studying the global behavior of the Earth crust from gravity observations. Here, we recall that the Marussi tensor is the gravity gradient tensor, which is traceless and symmetric. In the present research, subducting plates are modelled by dipping prisms. Because of its simplicity, this modelling can be used on a global basis and will give us the chance to improve the GEMMA global Moho [Reguzzoni and Sampietro, 2015] by better reducing the GOCE data before inverting them. According to the dipping prism modelling, GOCE gravity gradients along the orbit are used to estimate the shape, size, and orientation parameters of the studied subduction plate along with its density contrast. Note that, even if in correspondence of the subducting plates several density contrasts are present, e.g. the one related to the accretionary wedge, or to the magma melting and diapirism [Lallemand et al., 1992; Behn et al., 2011], here we will consider just the contrast between the subducting crust and the surrounding lithosphere (see Figure 2). This approximation is justified by the fact that a detailed modelling of each subduction zone for global studies is a very difficult task, which is in general not required due to the low spatial resolution of such global crustal studies.

The proposed algorithm is tested by studying the Tonga subduction zone, located where the Pacific plate subducts beneath the Australian one at the Tonga and Kermadec trenches and dips to the West direction generating one of the most active tectonic complexes in the world [Van Der Hilst, 1995]. The Kermadec-Tonga subduction zone is characterized as a convergent plate boundary, which stretches from the North Island of New Zealand northward, and includes the Hikurangi Trough, and the Kermadec and Tonga Trenches [Ewart et al., 1977]. Along this zone, the Pacific plate to the East is subducting beneath the Indo-Australian plate at a rate of 5.5 to 7.4 centimetres per year [Garcia-Castellanos et al., 2000].

In Section 2, the data reduction to isolate the subduction anomalous signal and its inversion using a simulated annealing (SA) procedure are presented. In Section 3, the developed algorithm is applied on syn- 

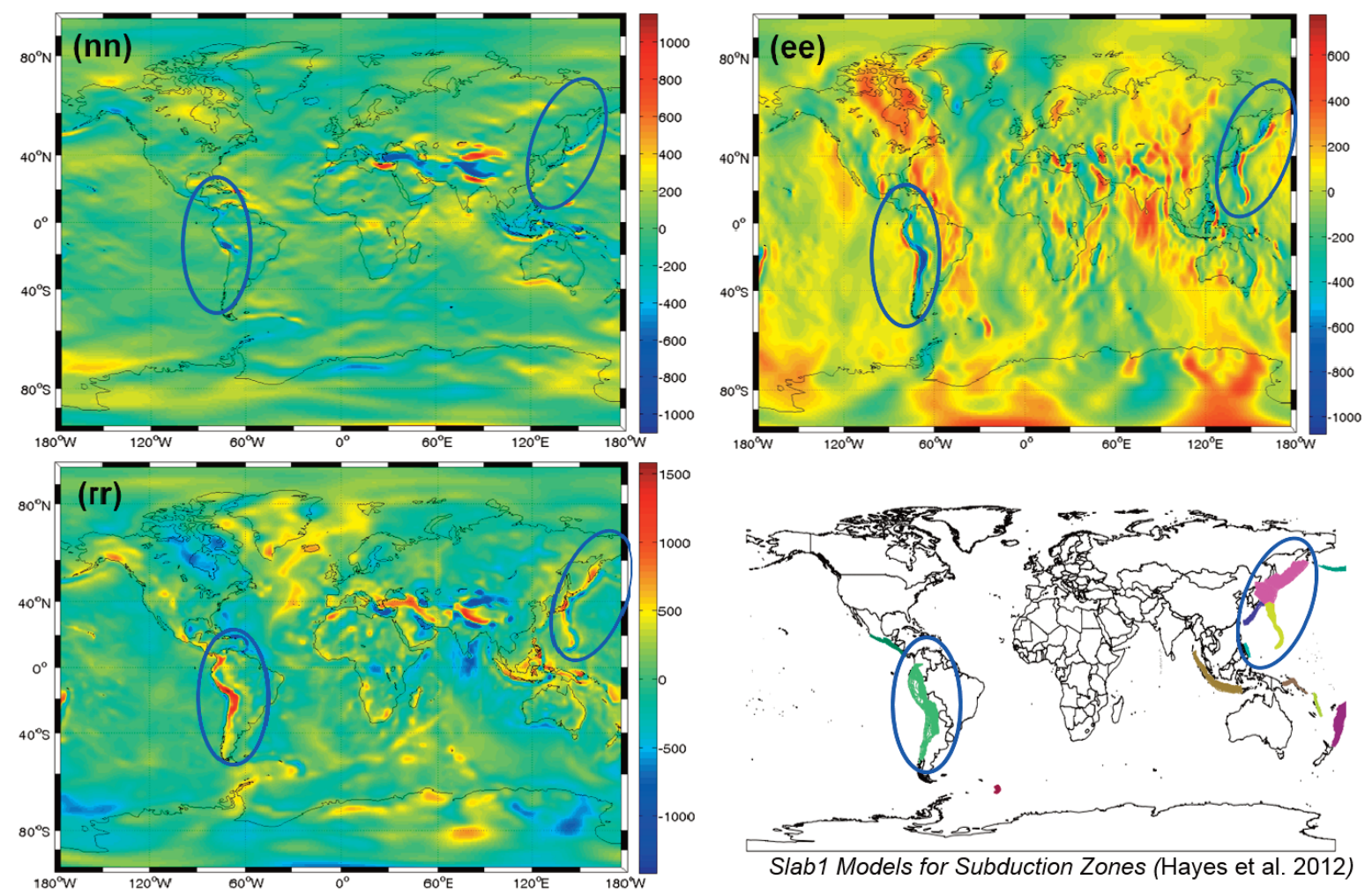

FIGURE 1. Grids of the Marussi tensor diagonal components computed from the time-wise GOCE-only model at satellite altitude [Brockmann et al., 2014]; units [mE], in comparison with the main subduction zones from the SLAB1.0 model.

thetic data in order to assess its performance in recovering the unknown subduction parameters and to evaluate the contribution of every single component of the gravity gradient tensor within the inversion procedure. Section 4 addresses the real-data processing and the consistency of the obtained results with those coming from existing seismic models. A final discussion on the obtained results is held in Section 5, confirming the feasibility of the proposed method and suggesting some possible improvements, too.

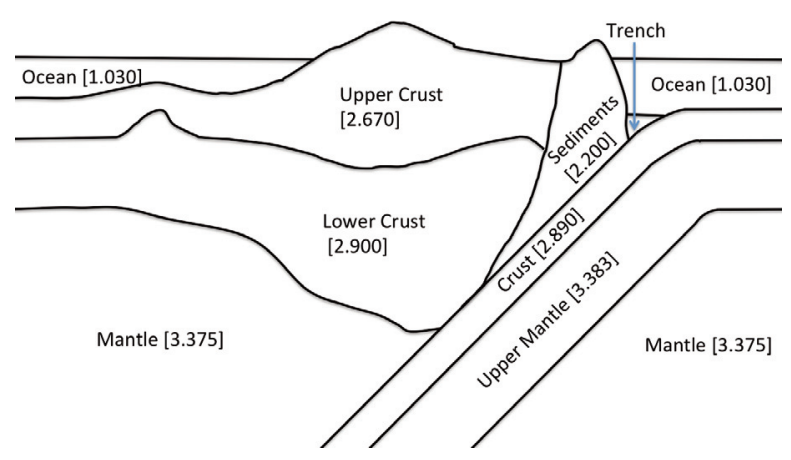

FIGURE 2. A simplified density model for the Tonga subduction complex, where all the density values are retrieved from the Preliminary Reference Earth Model (PREM) [Dziewonski and Anderson, 1981] but the density value of the oceanic crust from Carlson and Raskin (1984); units [g cm $\mathrm{cm}^{-3}$.

\section{METHODOLOGY}

As typical of inverse gravimetric problems, the proposed algorithm can be divided into two main steps, the former consists in the data reduction until the isolation of the gravitational signal due to the particular mass anomaly to be investigated, the latter deals with the inversion of the isolated/residual field and the retrieval of some characteristics of the mass anomaly under study [Li and Oldenburg, 1998].

\subsection{DATA REDUCTION AND SUBDUCTION EFFECT ISO- LATION}

We will consider as observations a functional of the gravitational potential measured on a set of sparse points at satellite altitude and distributed all around the world (to fix the idea one can think to the second radial derivative of the gravitational potential observed by the GOCE satellite). In order to fulfil the first step of the proposed procedure, i.e. to isolate the gravitational signal due to the investigated subduction zone, the gravitational effects of all the mass anomalies, apart from those of the subducting plate itself, should be modelled, preferably from gravity independent information, and then removed from the observations [Forsberg et al., 2002; Sampietro et al., 2016; Capponi et al., 2017; Mansi et al., 2018; Sampietro et al., 2018-a; Zaki 
et al., 2018-a; Zaki et al., 2018-b]. In principle, this step leaves as unknowns only a set of parameters modelling the mass distribution related to the presence of the subducting plate, thus reducing the space of the possible solutions, that is in general of infinite dimensions in the case of the inverse gravimetric problems [Sampietro and Sansò, 2012]. As said before, since the aim of this paper is to find a simplified way to model subduction plates (from the gravitational point of view), we will just consider the crust-mantle density contrast neglecting any other existing crustal inhomogeneities. As well-known, this is a thorny issue due to the fact that such a kind of information is actually not available (at least on a global scale) with sufficient accuracy. Nonetheless, we start by modelling and removing from the observations the most external, and therefore probably the most reliable, layers: namely, the gravitational effects of topography, bathymetry, and sediments.

For this purpose, the ETOP01 global relief model [Amante and Eakins, 2009] distributed by the National Geophysical Data Center (NGDC), with a spatial resolution of $0.5^{\circ} \times 0.5^{\circ}$, was used to compute the gravitational effects of land topography, ocean bathymetry, and ice surface (top of Antarctic and Greenland ice sheets) on a global spherical grid at a mean altitude of $10 \mathrm{~km}$, i.e. on a so-called Brillouin sphere [Sansò and Sideris, 2013]. This altitude has been chosen since, in this way, the corresponding sphere is just outside the Earth's masses but it is close to them thus avoiding a too strong smoothing effect. The global gravitational effects have been computed by means of point-mass approximation as described in Reguzzoni et al. [2013], in details more than 180 million point masses have been used to produce a global grid of the second radial derivatives of the gravitational effects of the ETOPO1 model at $10 \mathrm{~km}$ altitude with an expected accuracy better than $0.5 \mathrm{mE}$ $\left(1 \mathrm{mE}=10^{-12} \mathrm{~s}^{-2}\right)$. The same procedure has been applied to the CRUST1.0 sediment models [Laske et al., 2013]. Once computed, both signals have been removed from the actual dataset thus obtaining a reduced global grid of the second radial derivatives.

From this grid, a set of spherical harmonic coefficients up to degree and order 360 were computed by performing a spherical harmonic analysis according to Colombo [1981] and Reguzzoni [2004].

At this point, we have removed the contributions of these layers from the GO_CONS_GCF_2_TIM_R5 GOCE global model [Brockmann et al., 2014] and we synthesized a grid of the second radial derivatives of the anomalous gravitational potential at GOCE mean satellite altitude, $h=250 \mathrm{~km}$, from the residual coefficients. In this way, we obtain the gravitational effects of an
Earth model "without" topography, bathymetry, icesheets, and sediments, in terms of the most informative GOCE observables. The residual gravity signal is basically the sum of the effects of the subduction and of the crust-mantle interface. In particular, the latter term is expected, apart from anomalous regions, to be a smooth signal. The same holds also for the major density variations in the lithosphere. The main task, at this time, is to stochastically exploit some properties of the residual field, such as its spatial correlation, in order isolate the gravitational effects of the subducting crust, which, vice-versa, is a sharp variation of mass density (see Figure 2), producing a quite sharp variation in the gravitational field. Moreover, exploiting the statistical properties of the reduced data decreases the signal that could be mistakenly considered as noise, in the sense of coloured noise, or as a residual effect of the isolated signal, i.e. due to the subduction plate [Braitenberg, et al., 2016; Sampietro, et al., 2017].

For this reason and in order to disentangle the different contributions inside the reduced gravitational signal, the procedure, summarised in Figure 4, has been applied as thoroughly explained in the sequel:

1) a mask is created within the region where the subduction zone is expected to be;

2) the empirical semi-variogram of the reduced gravitational field is estimated using the observation points located close to the subduction region but yet outside the mask;

3) a Kriging procedure is used to predict the signal inside the mask.

The Kriging estimate [Wackernagel, 2013] allows obtaining the gravitational field of a "regular" crust, i.e. a signal where the effects of the subduction are not evident.

The procedure was empirically tested on the Kermadec-Tonga subduction zone. Basically, starting from the reduced second radial derivative of the anomalous gravitational potential, $T_{r r}$, synthesized on a regular grid with a resolution of $0.5^{\circ}$ at $250 \mathrm{~km}$ altitude (see Figure 3-a) and considering the information coming from the SLAB1.0 model, the mask shown in Figure 3$b$ has been empirically defined.

At this point, the empirical semi-variogram, providing information on the spatial autocorrelation of our dataset, was built as:

$\gamma\left(d_{12}\right)=1 / 2 E\left[\left(T_{r r}\left(P_{1}\right)-T_{r r}\left(P_{2}\right)\right)^{2}\right]$

where $d_{12}$ is the spherical distance between two points outside the masked region, namely $\mathrm{P}_{1}=\left(\lambda_{1}, \varphi_{1}, h_{1}\right)=\left(\lambda_{1}^{\mathrm{c}}, \varphi_{1}^{\mathrm{c}}, r_{1}^{\mathrm{c}}\right)$ and $P_{2}=\left(\lambda_{2}, \varphi_{2}, h_{2}\right)=$ $\left(\lambda_{2}^{\mathrm{c}}, \varphi_{2}^{\mathrm{c}}, r_{2}^{\mathrm{c}}\right)$, where $\lambda, \varphi$ and $h$ are the geodetic longi- 

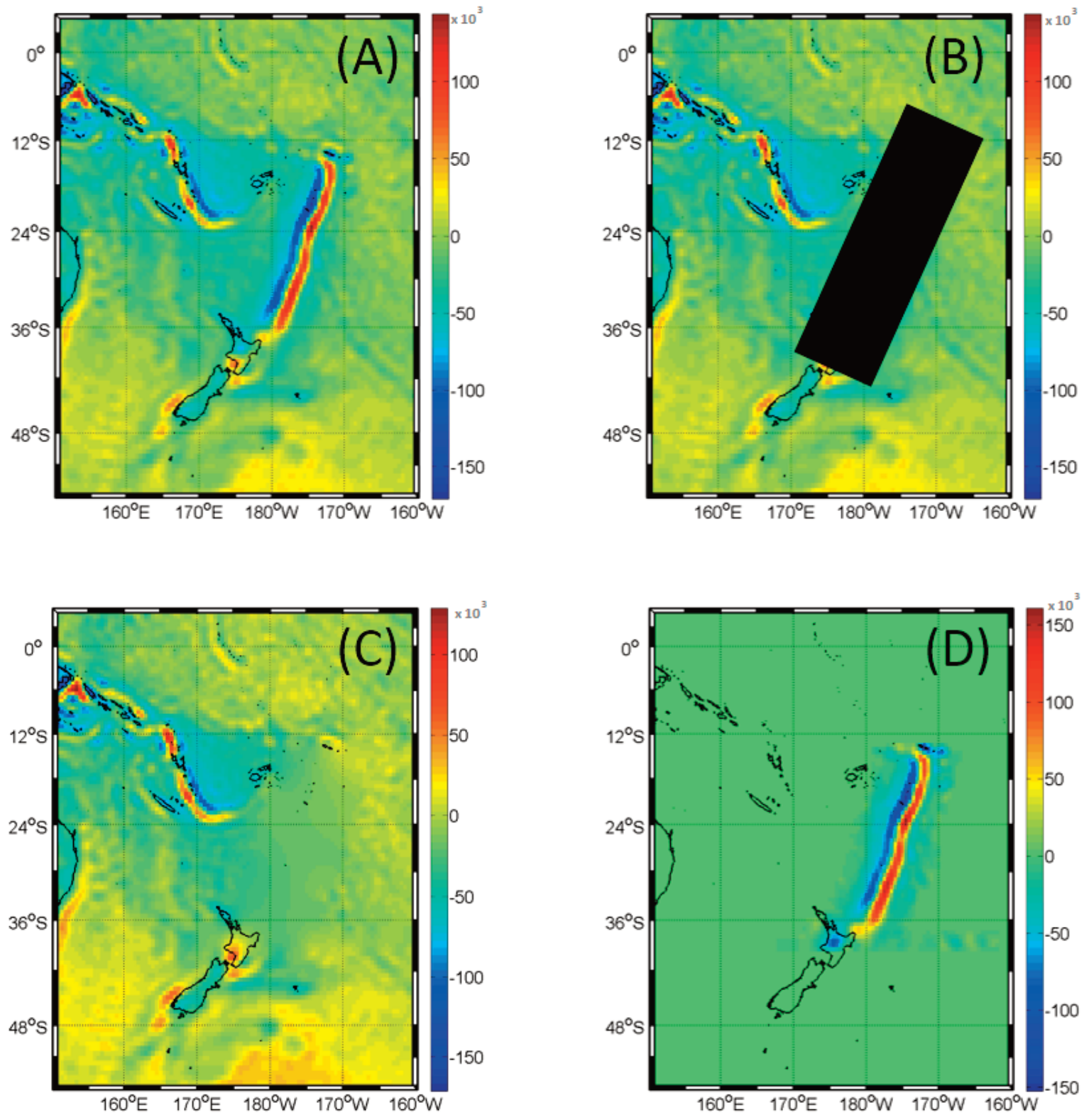

FIGURE 3. Steps for data reduction and isolation of the Tonga subduction zone gravitational field: (A) GOCE $T_{r r}$ signal at satellite altitude reduced for the effects of topography, bathymetry, ice sheets, and sediments; (B) the region used for the semivariogram computation excluding the points located within the mask in black; (C) the "regular" crust signal computed by Kriging to fill in the mask in (B); and (D) the isolated Tonga $T_{r r}$ signal computed by subtracting the signal in (C) from the reduced GOCE $T_{r r}$ signal in (A); units [mE].

tude, latitude, and ellipsoidal height and $\lambda^{\mathrm{c}}, \varphi^{\mathrm{c}}$ and $r$ are the geocentric longitude, latitude, and radius, and $E[\cdot]$ is the Expectation operator.

The spherical distance $d_{12}=\sqrt{r_{1}^{2}}+r_{2}^{2}-2 r_{1} r_{2} \cos \psi$, where $\cos \psi=\cos \varphi_{1} \cos \varphi_{2} \cos \overline{\left(\lambda_{1}-\lambda_{2}\right)+\sin \varphi_{1} \sin \varphi_{2} \text {. }}$

The transformation from the geodetic, i.e. ellipsoidal, coordinate system to the geocentric system can be achieved using the following equations:

$N=\frac{a}{\sqrt{1-e^{2} \cdot \sin \varphi}}$

$$
\begin{aligned}
& \varphi^{\mathrm{c}}=\tan ^{-1}\left(\frac{N\left(1-e^{2}\right)+h}{N+h} \cdot \tan \varphi\right) \\
& \lambda^{\mathrm{c}}=\lambda \\
& r=\sqrt{((N+h) \cos \varphi)^{2}+\left(\left(N\left(1-e^{2}\right)+h\right) \sin \varphi\right)^{2}}
\end{aligned}
$$

where, given a reference ellipsoid, $a$ and $b$ are respectively the semi-major and semi-minor axes, $e=\sqrt{1-\frac{b^{2}}{a^{2}}}$

is the (dimensionless) first eccentricity, and $N$ is the East-West radius of curvature.

The empirical semi-variogram $\gamma\left(d_{12}\right)$ was fit with a 
theoretical one, in particular, many different models (e.g. bilinear, circular, spherical, pentaspherical, exponential, Gaussian, Whittle, Stable, and Matern [Wackernagel, 2013]) were tested and the best fitting, namely the exponential one, was chosen (see Figure 5). Using this theoretical semi-variogram function, the gravitational signal has been predicted by means of a standard Kriging solution (3) inside the mask, thus finding an estimated effect for the so-called "regular" crust (Figure $3-c)$ :

$\hat{T}_{j j}\left(P_{0}\right)=\sum_{i=1}^{M} W_{i} T_{j j}\left(P_{j}\right)$

where $\hat{T}_{j j}$ is the interpolated value at point $P_{0}$, located inside the mask, using the measured values $T_{j j}$, i.e. gravity second derivatives with respect to the $j$ direction, namely East, North, and radial components, at points $P_{i}$, where $i=1,2,3 \ldots M$, in which the number of points $n$ inside the mask is much smaller than the number of observations $M$, and $W_{i}$ is the weight of the measured value at the $i^{\text {th }}$ location. The weights are obtained by solving the system reported in (4):

$$
\begin{aligned}
& \sum_{i, k=1}^{M} W_{i} \gamma\left(d_{i k}\right)+\lambda=\gamma\left(d_{i 0}\right) \\
& \sum_{i=1}^{M} W_{i}=1
\end{aligned}
$$

where $\lambda$ is a Lagrange multiplier used for the estimation error minimization, $\gamma\left(d_{i k}\right)$ is the value of the semi-variogram model for the distance $d_{i k}$ between the $i^{\text {th }}$ and $k^{\text {th }}$ observations, and $\gamma\left(d_{i 0}\right)$ is the value of the semivariogram model for the distance $d_{i 0}$ between the $i^{\text {th }}$ observation and the point $P_{0}$ inside the mask. For details on the Kriging solution, the interest reader is referred to Wackernagel [2014].

Finally, the effect of the subduction is isolated by removing this signal from the originally synthesized $T_{r r}$ (Figure 3-d). Even though the topography/bathymetry gravitational effects were removed, a high-frequency signal in correspondence with the Tonga-Kermadec trench and arc is still well-visible, negatively affecting the subsequent inversion. This is probably because of the presence of non-regular structures of the crust in correspondence of subducting plates, such as the accretionary wedge or the magmatic arc, that are not taken into account in the reduction procedure. For example, Crawford et al. [2003] showed crustal thickness variations from more than $20 \mathrm{~km}$ to roughly $5 \mathrm{~km}$ over short spatial scales, which are obviously not included into our "regular" crust.

Note that this procedure could be directly applied to the observed gravity gradients instead of the synthesized grid of second radial derivative. However, in this way, one has to face the problem that along-orbit data are at different altitudes and therefore the semi-variogram cannot, in principle, depend on the spherical distance only.

In order to assess the validity of the proposed procedure, a numerical test has been executed: basically, we randomly moved the defined mask in oceanic regions and we repeated the Kriging procedure. The basic idea is to verify the capabilities of the Kriging predictor to estimate the gravitational signal due to what we have called "regular" crust. This test shows that where the mask does not coincide with a subduction zone, the Kriging solution is able to predict the actual gravitational field with an accuracy of about $10.3 \mathrm{mE}$, in terms of standard deviation (STD). On the contrary, when the mask is located over a subduction zone, the residual signal shows a much higher STD value, e.g. over the Tonga subduction zone, the STD is $345 \mathrm{mE}$.

The whole procedure used to isolate the gravitational signal of the subduction plate is summarised in Figure 4 , where it can be seen how the final signal used within the inversion is, basically, the difference between the

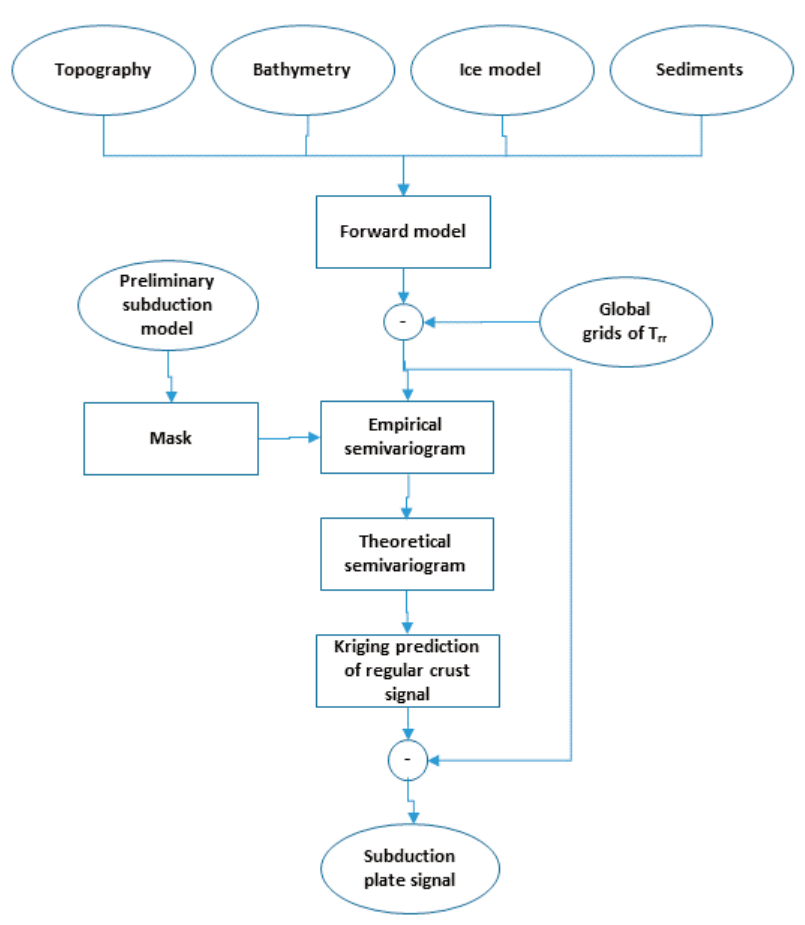

FIGURE 4. Flowchart of the procedure used to isolate the gravitational signal of the subduction plate. 
observations reduced for the effects of the topography, bathymetry, ice model and sediments and the Kriging estimate of the "regular" crust.

\subsection{INVERSION}

The procedure to isolate the subduction signal explained above is based on the use of the GO_CONS_GCF_2_TIM_R5 GOCE global model. However, the aim of this work is to investigate the information content of the GOCE gravity gradients observed along the satellite orbit. For this reason, in order to "move" the estimated gravity effects of the "regular" crust into the sparse points along the orbit, the Kriging procedure has been applied all over the sphere and the resulting global grid has been analyzed in terms of spherical harmonic coefficients, as already done while computing the contributions of the topography, bathymetry, etc. Attention has to be paid to the fact that the results of this global Kriging interpolation represent the actual "regular" crust effects only within the study area, as shown in Figure 6. Of course, for the study of other subduction zones, the spherical harmonic coefficients of the "regular" crust would be different.

Before applying the inversion, the observed gravity gradients are reduced for the effects of the "regular" crust as well as the topography, bathymetry, and sediments, where their effects were synthesized from the corresponding spherical harmonic coefficients. In this way, the gravitational signal due to the density variation between the subducting plate and the mantle is isolated from the rest of the observed signal.

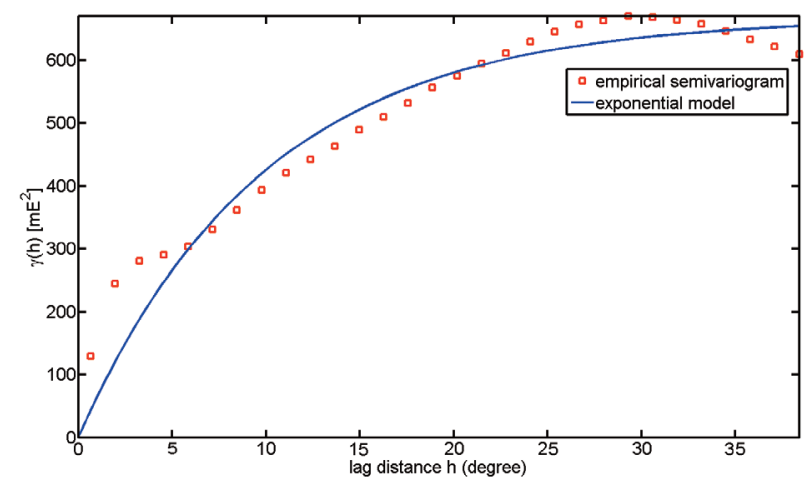

FIGURE 5. The empirical (red squares) and the theoretical (blue curve) semi-variogram of the reduced second radial derivative $T_{r r}$.

Hence, it is possible to apply the inversion algorithm. Here, the main challenge is to find a methodology to dominate the well-known instability of such kind of inversion problems. In this sense, to further reduce the space of the possible admissible solutions, a simplified model that depends on a small number of unknown parameters was required. Actually, one of the simplest models to describe a subducting plate is to model it as a dipping prism, which depends only on a set of eight unknown parameters (see Figure 7), namely:

$-x$ coordinate of the centre of the top face;

$-y$ coordinate of the centre of the top face;

- length $(\Delta x)$;

- width $(\Delta y)$;

- depth $(\Delta z)$;

- dipping angle $(\alpha)$;

- striking angle $(\beta)$;

- the constant density contrast between the dipping prism and the surrounding layer $(\Delta \rho)$.

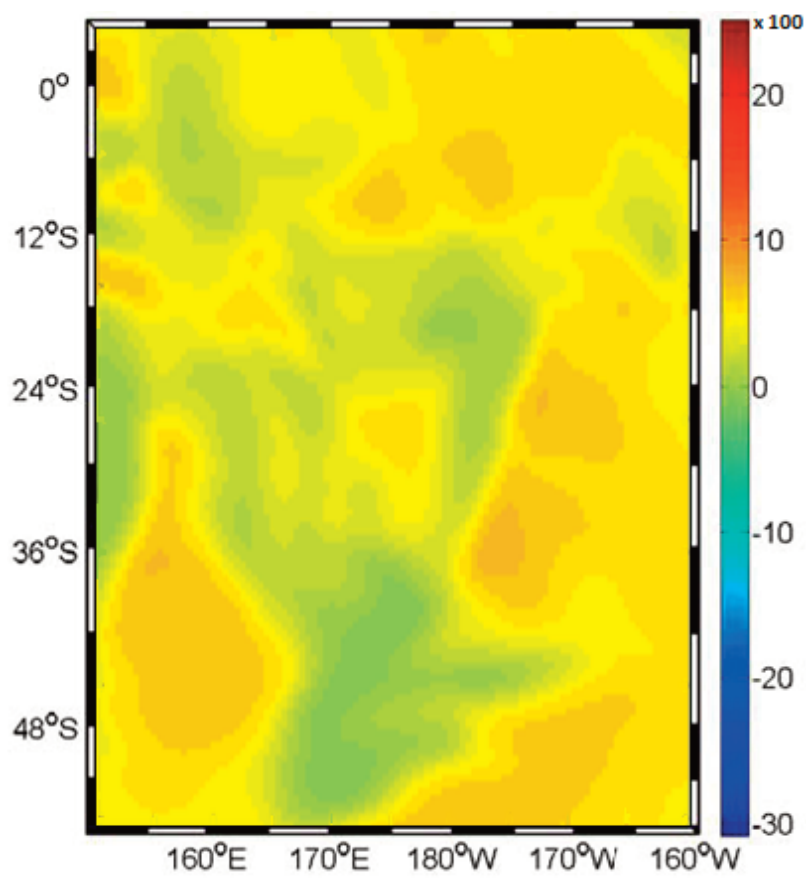

FIGURE 6. The "regular" crust effects in terms of the second radial derivatives, $T_{r r}$, for the Tonga subduction; units [mE].

The Cartesian coordinates $(x, y, z)$ are simply obtained by mapping the geodetic coordinates $(\lambda, \varphi, h)$ according to the following transformation equations:

$x=R \cos \bar{\varphi}(\lambda-\bar{\lambda})$
$y=R(\varphi-\bar{\varphi})$
$z=h$

where $\lambda, \varphi$ and $h$ are the geodetic longitude, latitude, and ellipsoidal height, respectively, $\bar{\lambda}$ and $\bar{\varphi}$ are the longitude and latitude of the center of the study area, and 
$R$ is the radius of the local sphere defined as:

$R=\frac{a^{2} b}{(a \cos \bar{\varphi})^{2}(b \cos \bar{\varphi})^{2}}$

Note that, the three axes of the obtained Cartesian reference frame are almost pointing to the East, North and up direction, respectively.

In regards to the dipping prism model, it should be underlined that this approximation has a major modelling advantage that allows an exact forward modelling of its gravitational field: in fact, a closed-form solution for the direct computation of the gravitational signal of a dipping prism was derived by Hjelt [1974]. However, in this work, we compute the gravitational effect using the point-mass approximation and we use the closed-formula only to check the accuracy of the forward modelling. Later on, in fact, the point-mass approximation could allow modelling the gravitational effects of anomalies depicted also with more complex shapes than a dipping prism, e.g. a dipping angle increasing with depth. Whatever forward modelling technique is used, the relationship between the unknown parameters and the observed gravitational field is strongly non-linear. Therefore, we decided to apply a SA procedure [Bertsimas and Tsitsiklis, 1993; Rossi et al., 2015] to find the set of parameters $S$ that best fits the isolated subduction signal (target signal). The Matlab implementation of the algorithm was used [Ingber, 1996]. Necessarily, the system must be initialized by imposing $S$ equal to a certain set $S_{0}$. Afterwards, a randomly chosen neighbourhood of $S_{0}$ (for instance, call it $S_{1}$ ) is drawn, the corresponding gravitational signal $\hat{T}_{r r}\left(S_{1}\right)$ is computed and finally, the goodness of the solution is evaluated according to the following target function $F$ :

$F\left(S_{1}\right)=\left(T_{r r}-\hat{T}_{r r}\left(S_{1}\right)\right)^{T} C_{r r}^{-1}\left(T_{r r}-\hat{T}_{r r}\left(S_{1}\right)\right)$

where $T_{r r}$ is the vector of the observed (target) second radial derivative of the reduced gravitational signal, $\hat{T}_{r r}\left(S_{1}\right)$ is the predicted signal obtainable from the forward modelling of state $S_{1}$ of the SA algorithm, and $C_{r r}$ is the observation error covariance matrix. According to the Metropolis-Hastings algorithm [Hastings, 1970], the state $S_{1}$ replaces the current state $S_{0}$ if the new state has a smaller $F$ value than the older one or if it passes an acceptance function. After that, the whole procedure is iterated until convergence is met.

The acceptance function and the size of the neighbourhood space, from which the new state is drawn, are in proportional to a given parameter $T$ (usually called "temperature"), which is decreased at each iteration ac- cording to a given cooling rule. The selection of the cooling function is an essential milestone in the performance of the SA algorithm. The decreasing temperature tends to force the current state towards the minima, moving only downhill. Decreasing the temperature too quickly could result in the state getting trapped in a local minimum, while decreasing it too slowly seems to waste the computational power through a very slow convergence [Kannan and Lakshmikantham, 2002]. The choice of the most suitable cooling rule for the above procedure is based on a closed-loop test that will be discussed in the next section.

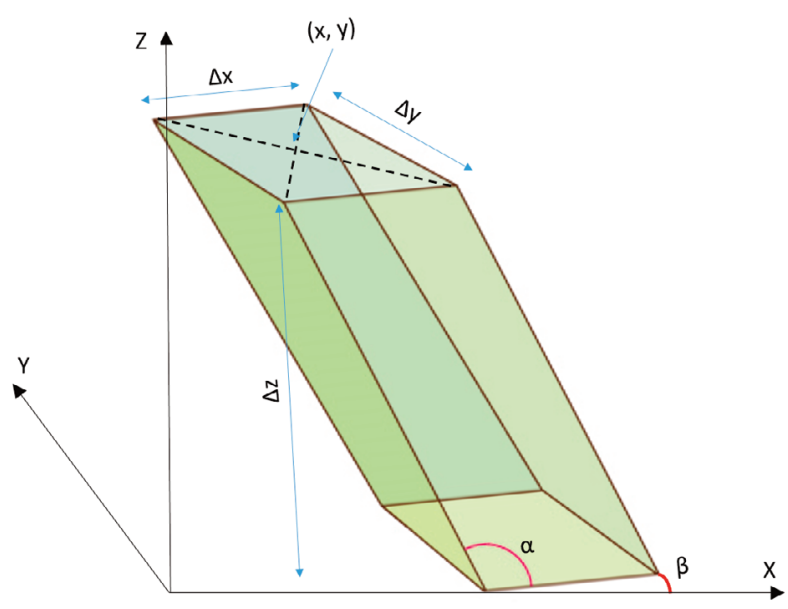

FIGURE 7. The dipping prism model defined by 8 parameters.

\section{CLOSED-LOOP TEST ON SYNTHETIC DATA}

Before applying the proposed method to real GOCE data of a particular subducting plate, it was worthwhile to assess the algorithm and test its performance on a synthetic-realistic dataset. The closed-loop test basically consists of building a synthetic subducting plate, with perfectly known geometry, simulating its gravitational signal, adding some noise, and applying the proposed inversion procedure. First of all, this permits to numerically assess the inversion strategy. Secondly, since the GOCE mission delivered six different kinds of along-orbit data, namely all the components of the Marussi tensor, the test could be also used to understand if some gravity gradients are more informative than others and, in case, to properly set the combination weights of all the different tensor components. In particular, we consider the three diagonal components of the Marussi tensor, namely $T_{e e}, T_{n n}$, and $T_{r r}$, adding to the observations a $3 \mathrm{mE}$ white noise, where $e, n$ and $r$ stay for the East, North, and radial directions of the local triad. 
Again, we chose the Tonga subduction and the parameters used to simulate the plate were picked from the literature [Nothard et al., 1996; Astiz et al., 1988] and reported in the first row of Table 1 . The experiment has been repeated more than 100 times changing the realization of the noise in order to be able to statistically assess the performance. As for the cooling function required by the SA procedure, here the Boltzmann cooling function [Geman and Geman, 1993] has been adopted, as follows:

$T_{i}=\frac{T_{0}}{\log (i+1)} \quad i=1,2,3, \ldots$

where $T_{0}$ is the initial temperature constant for $i=0$.

Among the different cooling rules, in fact, the Boltzmann function led the system to the final state with the lowest value of the target function, consequently showing the best capability to converge towards the original parameters used to generate the simulated signal of the closed-loop test. Results in terms of STD of the differences between the true parameters and the estimated ones are also reported in Table 1 . Generally speaking, it can be seen that each gradient has different sensitivities to the different parameters. In details, $T_{r r}$ is highlysensitive to all the parameters. On the other hand, regarding the $T_{e e}$ and $T_{n n}$ components, both show higher sensitivities to the parameters related to the perpendicular direction. For example, $T_{e e}$ gives a better prediction for the length in the $\mathrm{X}$ direction $(\Delta x)$ and the strike angle $(\beta)$ than $T_{n n}$, which, in turn, is more sensitive to the width in the $\mathrm{Y}$ direction $(\Delta y)$, the dipping angle $(\alpha)$, and the $y$ coordinate of the top face center than $T_{e e}$. Obviously, the aforementioned sensitivities highly-depend on the location and the geometry of the investigated subduction zone, for instance, for the striking angle $(\beta)$, it is evident that a rotation of $90^{\circ}$ of the dipping prism around the $\mathrm{Z}$ axis will basically exchange the rules of $T_{e e}$ and $T_{n n}$.

Starting from the above results, it was possible to build a combined solution able to optimally exploit the information coming from the three different observables of the main diagonal. In this research, the final solution is computed as a weighted average of the three individual solutions with the weights obtained for each unknown parameter defined as:

$W_{j j}(i)=\frac{\frac{1}{\sigma_{j j}(i)}}{\frac{1}{\sigma_{e e}(i)}+\frac{1}{\sigma_{n n}(i)}+\frac{1}{\sigma_{r r}(i)}} \quad j=e, n, r \ldots$

where $\sigma_{j j}(i)$ is the STD of the results obtained using the gravity gradients with respect to the $j$ direction for the $i^{\text {th }}$ parameter of the dipping prism according to the ordering used in Table 1.
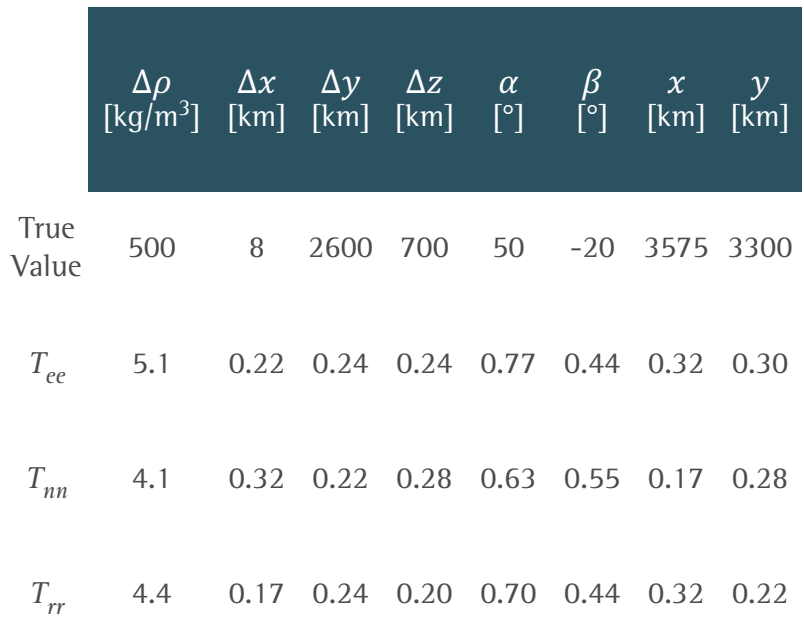

TABLE 1. The standard deviation of the differences between true parameters and the estimated ones.

\section{THE KERMADEC-TONGA SUBDUCTION CASE}

The Kermadec-Tonga region extends from about $170^{\circ} \mathrm{E}$ to $170^{\circ} \mathrm{W}$ and $40^{\circ} \mathrm{S}$ to $10^{\circ} \mathrm{S}$. It represents an ideal natural laboratory to study the presented inversion scheme for several reasons. The existence of a subduction zone has been thoroughly studied using various seismological investigations [e.g., Oliver and Isacks, 1967; Mitronovas et al., 1969; Sykes et al., 1969; Mitronovas and Isacks, 1971; Barazangi et al., 1972]. The geometry of this subduction is fairly simple and well-studied [Bowman and Ando, 1987]. A large portion of the world deep earthquakes occurs in the subducted slab in the Fiji deep seismic zone, and islands are located close to the deep earthquake epicentres, which allows recording in the shear-wave window.

From the gravitational point of view, this region is characterized by the presence of a series of geophysical signals at very different frequencies [Billen et al., 2003; Conder and Wiens, 2006], where the very long-wavelengths (of the order of a few thousand kilometres) are dominated by the density heterogeneities inside the mantle. Superimposed on this long-wavelength signal, the Kermadec-Tonga and New Hebrides Trenches are marked by a high frequency (short-wavelength) signal. The observed bathymetry is dominated by short-to-intermediate-wavelength (500 to $1000 \mathrm{~km}$ ) signals caused by the crustal thickness variations, including the con- 
tinental fragments making up New Zealand (Chatham Rise, Campbell Plateau, and Lord Howe Rise), and owing to the variation in lithospheric age, including the very young back-arc spreading centers above the KermadecTonga and New Hebrides subduction zones (Lau Basin, Havre Trough, and Fiji Basins).

After checking the performance of the implemented algorithm by the closed-loop test, the synthetic signals have been replaced by the real ESA-GOCE along-orbit gravity gradients dataset and a solution for the Tonga subduction has been computed. In particular, the EGG_TRF_2 dataset [Bouman, et al., 2011] has been used instead of the original EGG_NOM_2 data [Rummel, et al., 2011]. For these data, a white noise has been assumed in the minimization of the three target functions (see (7) for the $T_{r r}$ component). The inversion has been done targeting three individual solutions, namely a solution for each of the diagonal component of the Marussi tensor. Once computed, these three individual solutions have been merged by means of a weighted average using the weights resulted from the closed-loop tests (see (9). This procedure, namely the computation of a solution for each diagonal component of the Marussi tensor and the subsequent combination, allows to increase the observation number and to execute in parallel the three SA optimizations.

The signal due to the subduction, as isolated by the Kriging procedure, is shown in Figure 3-d. It can be seen how the proposed algorithm allows to basically remove the middle-low frequencies dominated by crustal thickness variations and mantle heterogeneities, thus highlighting the effects of the subduction (it is important to underline that the gravitational effects of topography, bathymetry and sediment layers were removed before applying the Kriging procedure). As already stated before, a high-frequency signal that corresponds to the Tonga-Kermadec trench and arc is not fully removed and it will be misinterpreted as the signal of the subduction plate. However, it should be observed that this high-frequency signal is expected to have just minor effects on the estimation of the parameters of our simple dipping prism model. The parameters estimated by inverting the three diagonal components of the Marussi tensor, namely the $T_{e e}, T_{n n}$, and $T_{r r}$, as well as the combined solutions, are reported in Table 2.

It can be noted that there is a good agreement, in general, among the three different solutions for $\Delta x, \Delta y$, $\Delta z, x$, and $y$ with differences smaller than $10 \%$ with respect to the combined solution. As for the other parameters, namely $\Delta \rho \alpha$ and $\beta$, it seems that the $T_{n n}$ solution significantly deviates from the other ones with differences going up to about $60 \%$ with respect to the density contrast, $40 \%$ for the strike angle $\beta$, and $15 \%$ for the dipping angle $\alpha$. This can be ascribed to the geometry of the subducting plate that mainly develops in the North-South direction, making the $T_{n n}$ signal smaller than the other components. As a consequence, the impact of the non-perfect isolation of the subducting plate as well as the simplification introduced by modelling the plate with a single dipping prism are amplified, thus degrading the quality of the inversion of the $T_{n n}$ component.

\begin{tabular}{|c|c|c|c|c|c|c|c|c|}
\hline & $\begin{array}{c}\Delta \rho \\
{\left[\mathrm{kg} / \mathrm{m}^{3}\right]}\end{array}$ & $\begin{array}{c}\Delta x \\
{[\mathrm{~km}]}\end{array}$ & $\begin{array}{c}\Delta y \\
{[\mathrm{~km}]}\end{array}$ & $\begin{array}{c}\Delta z \\
{[\mathrm{~km}]}\end{array}$ & $\begin{array}{c}\alpha \\
{\left[{ }^{\circ}\right]}\end{array}$ & $\begin{array}{c}\beta \\
{\left[{ }^{\circ}\right]}\end{array}$ & $\begin{array}{c}x \\
{[\mathrm{~km}]}\end{array}$ & $\begin{array}{c}y \\
{[\mathrm{~km}]}\end{array}$ \\
\hline $\begin{array}{l}\text { True } \\
\text { Value }\end{array}$ & - & - & - & $\begin{array}{c}670^{(1)} \\
\text { to } \\
700\end{array}$ & $\begin{array}{l}40 \text { to } \\
55^{(2)}\end{array}$ & $\begin{array}{l}-20 \\
\text { to } 16\end{array}$ & - & - \\
\hline$T_{e e}$ & 464 & 7.4 & 2569 & 718.5 & 35.5 & -22.1 & 3633 & 3411 \\
\hline$T_{n n}$ & 147 & 7.1 & 2612 & 679.4 & 47.4 & -35.1 & 3633 & 3412 \\
\hline$T_{r r}$ & 4.3 & 7.0 & 2598 & 698.0 & 42.3 & -21.1 & 3630 & 3390 \\
\hline Comb. & 382 & 7.1 & 2596 & 702 & 40.6 & -24.0 & 3632 & 3407 \\
\hline
\end{tabular}

TABLE 2. The three individual solutions and the combined one in comparison with the Slab1.0 model, (1) according to Nothard et al. [1996], and (2) according to Astiz et al. [1988].

In any case, these results also show how the use of the three different functionals of the gravitational field makes the final solution more robust since the effect of possible mis-modelling acts differently on the components of the Marussi tensor. The use of these thre second derivatives of the gravitational potential produces a final result that is in a good agreement with the literature values. For instance, the depth value $\Delta z$ of the Tonga plate ranges between $670 \mathrm{~km}$ in Nothard et al. [1996] and about $700 \mathrm{~km}$ in the SLAB1.0 model [Hayes et al., 2012], which is in a good agreement with the 702 $\mathrm{km}$ of the combined solution. Similarly, the dipping angle $\alpha$, which is $40.6^{\circ}$, is in a good agreement with the values reported by Astiz et al. [1988] and the SLAB1.0 
model (which range between $40^{\circ}$ and $55^{\circ}$ ). Also, an agreement with the SLAB1.0 model is found for the other planimetric parameters (namely $x, y$ and $\beta$ ). As for the remaining parameters, i.e. the density contrast $\Delta \rho$ and the length of the subducting plate $\Delta x$, since they cannot be observed by seismic data, no values have been found in the literature for a possible comparison.

\section{DISCUSSION AND CONCLUSIONS}

Although the complex shape of a subduction zone is highly simplified by a dipping prism or by a set of point-masses filling this dipping prism, the main estimated shape parameters, i.e. the planar extensions in the $\mathrm{X}$ and $\mathrm{Y}$ directions, prism depth, and both the dipping and strike angles, are in a relatively good agreement with the literature values. The overall differences between the obtained solutions and the seismic derived models with respect to the main planar parameters are less than 10\%. The use of all the Marussi tensor diagonal components, in principle, gives a more robust solution due to the different sensitivity of each component towards each single model parameter.

Moreover, the results show how, with the advent of GOCE observations, gravity can give new useful information to improve our knowledge about subduction plates and tectonic dynamics, thus encouraging this kind of activities. In fact, regardless the ill-posed characteristics of the gravitational field inversion, an adequate gravity-related inversion technique would allow to retrieve information on the plate's density contrast with respect to the upper mantle, which cannot be recovered from seismic data.

The SA is capable to converge and estimate the set of parameters generating the target signal with an acceptable error margin. For future research, the gravity inversion algorithm could be improved thanks to the SA capabilities of including numerical and physical constraints and implementing hybrid functions to improve the search of the global minima of non-linear functions.

The information content of the different GOCE along-orbit components is similar. Consequently, the use of a target function that jointly minimizes the three main components of the Marussi tensor, instead of a posteriori combining them, could lead to the estimation of a slightly different set of parameters.

This paper is largely a proof-of-concept for using the GOCE data to study subducting plate structures. Naturally, the inversion of a simple uniform density prism adds very little to the understanding of the Tonga subduction plate and does not fully exploit the high quality of the GOCE data. A possible future perspective could be to break the prism into several sub-prisms along the strike, thus increasing the number of parameters to solve, but offering the possibility of improving our understanding of the Tonga subduction complex and other plates more than a simple block prism ever could.

\section{REFERENCES}

Abrehdary, M., L. E. Sjöberg, M. Bagherbandi and D. Sampietro (2017). Towards the Moho depth and Moho density contrast along with their uncertainties from seismic and satellite gravity observations. J. Appl. Geodesy, 11(4), 101-115, doi: 10.1515/jag-2017-0019.

Amante, C. and B. Eakins (2009). ETOP01 1 arc-minute global relief model: procedures, data sources and analysis. Colorado: US Department of Commerce, National Oceanic and Atmospheric Administration, National Environmental Satellite, Data, and Information Service, National Geophysical Data Center, Marine Geology and Geophysics Division.

Astiz, L., T. Lay and H. Kanamori (1988). Large intermediate-depth earthquakes and the subduction process. Phys. Earth Planet. Inter., 53(1-2), 80166, doi: 10.1016/0031-9201(88)90138-0.

Bagherbandi, M., R. Tenzer, L. E. Sjöberg and P. Novák (2013). Improved global crustal thickness modeling based on the VMM isostatic model and nonisostatic gravity correction. J. Geodyn., 66, 25-37, doi: 10.1016/j.jog.2013.01.002.

Barazangi, M., B. Isacks and J. Oliver (1972). Propagation of seismic waves through and beneath the lithosphere that descends under the Tonga island arc. J. Geophys. Res., 77(5), 952-958, doi: 10.1029/JB077i005p00952.

Barzaghi, R., M. Reguzzoni, A. Borghi, C. I. De Gaetani, D. Sampietro and A. M. Marotta (2016). Global to local Moho estimate based on GOCE geopotential models and local gravity data. In N. Sneeuw, P. Novák, M. Crespi and F. Sansò, VIII HotineMarussi Symposium on Mathematical Geodesy, IAG Symposia, 142, 275-282, Springer, Cham, doi: 10.1007/1345_2015_15.

Behn, M. D., P. B. Kelemen, G. Hirth, B. R. Hacker and H.-J. Massonne (2011). Diapirs as the source of the sediment signature in arc lavas. Nat. Geosci., 4, 641-646, doi: 10.1038/ngeo1214.

Bertsimas, D. and J. Tsitsiklis (1993). Simulated Annealing. Statistical Science, 8(1), 10-15. 
Billen, M. I., M. Gurnis and M. Simons (2003). Multiscale dynamics of the Tonga-Kermadec subduction zone. Geophys. J. Int., 153(2), 359-388, doi: 10.1046/j.1365-246X.2003.01915.x.

Bouman, J., J. Ebbing, S. Meekes, R. A. Fattah, M. Fuchs, S. Gradmann, R. Haagmans, V. Lieb, M. Schmidt, D. Dettmering and W. Bosch (2015). GOCE gravity gradient data for lithospheric modeling. Int. J. Appl. Earth Obs., 35(Part A), 16-30, doi: 10.1016/j.jag.2013.11.001.

Bouman, J., S. Fiorot, M. Fuchs, T. Gruber, E. Schrama, C. Tscherning, M. Veicherts and P. Visser (2011). GOCE gravitational gradients along the orbit. J. Geodesy, 85(11), 791-805, doi: 10.1007/s00190011-0464-0.

Bowman, J. R. and M. Ando (1987). Shear-wave splitting in the uppermantle wedge above the Tonga subduction zone. Geophys. J. Int., 88(1), 25-41, doi: 10.1111/j.1365-246X.1987.tb01367.x.

Braitenberg, C., D. Sampietro, T. Pivetta, D. Zuliani, A. Barbagallo, P. Fabris, L. Rossi, J. Fabbri and A. H. Mansi (2016). Gravity for detecting caves: Airborne and terrestrial simulations based on a comprehensive Karstic cave benchmark. Pure Appl. Geophys., 173(4), 1243-1264, doi: 10.1007/s00024-015-1182-y .

Brockmann, J. M., N. Zehentner, E. Höck, R. Pail, I. Loth, T. Mayer-Gürr and W.-D. Schuh (2014). EGM_TIM_RL05: An independent geoid with centimeter accuracy purely based on the GOCE mission. Geophys. Res. Lett., 41(22), 8089-8099, doi: 10.1002/2014GL061904.

Capponi, M., A. H. Mansi and D. Sampietro (2017). Improving the computation of the gravitational terrain effect close to ground stations in the GTE software. Stud. Geophys. Geod., 62(2), 206-222, doi: 10.1007/s11200-017-0814-3.

Carlson, R. L. and G. S. Raskin (1984). Density of the ocean crust. Nature, 311, 555-558, doi: $10.1038 / 311555 a 0$.

Colombo, O. L. (1981). Numerical methods for harmonic analysis on the sphere. Report No. 310, Dept. of Geodetic Science and Surveying, The Ohio State University, Columbus.

Conder, J. A. and D. A. Wiens (2006). Seismic structure beneath the Tonga arc and Lau back-arc basin determined from joint Vp, Vp/Vs tomography. Geochem. Geophys. Geosyst., 7(3), Q03018, doi: 10.1029/2005GC001113.

Crawford, W. C., J. A. Hildebrand, L. M. Dorman, S. C. Webb and D. A. Wiens (2003). Tonga ridge and Lau basin crustal structure from seismic refraction data. J. Geophys. Res.: Solid Earth, 108(B4), 2195, doi: 10.1029/2001JB001435.

Deal, M. M., G. Nolet and R. D. van der Hilst (1999). Slab temperature and thickness from seismic tomography: 1. method and application to Tonga. J. Geophys. Res.: Solid Earth, 104(B12), 2878928802, doi: 10.1029/1999JB900255.

Drinkwater, M. R., R. Floberghagen, R. Haagmans, D. Muzi and A. Popescu (2003). GOCE: ESA's first Earth Explorer Core mission. In G. Beutler, M. R. Drinkwater, R. Rummel, and R. Von Steiger, Earth Gravity Field from Space - From Sensors to Earth Sciences, Space Sciences Series of ISSI, 17, 419432, Springer, Dordrecht, Netherlands, doi: 10.1007/978-94-017-1333-7_36.

Dziewonski, A. M. and D. L. Anderson (1981). Preliminary reference Earth model. Phys. Earth Planet Int., 25(4), 297-356, doi: 10.1016/00319201(81)90046-7.

Engdahl, E. R., R. van der Hilst and R. Buland (1998). Global teleseismic earthquake relocation with improved travel times and procedures for depth determination. Bull. Seism. Soc. Am., 88(3), 722-743.

England, P., R. Engdahl and W. Thatcher (2004). Systematic variation in the depths of slabs beneath arc volcanoes. Geophys. J. Int., 156(2), 377-408, doi: 10.1111/j.1365-246X.2003.02132.x.

Eshagh, M., M. Hussain, R. Tenzer and M. Romeshkani (2016). Moho density contrast in central Eurasia from G0CE gravity gradients. Remote Sens., 8(5), 418, doi: 10.3390/rs8050418.

Ewart, A., R. N. Brothers and A. Mateen (1977). An outline of the geology and geochemistry, and the possible petrogenetic evolution of the volcanic rocks of the Tonga-Kermadec-New Zealand island arc. J. Volcanol. Geotherm. Res., 2(3), 205250, doi: 10.1016/0377-0273(77)90001-4.

Forsberg, R., A. V. Olesen and K. Keller (2002). Airborne gravity survey of the north Greenland continental shelf. In M. G. Sideris, Gravity, Geoid and Geodynamics 2000, IAG Symposia, 123, 235-240, Springer, Berlin, Heidelberg, doi: 10.1007/978-3662-04827-6_39.

Garcia-Castellanos, D., M. Torne and M. Fernàndez (2000). Slab pull effects from a flexural analysis of the Tonga and Kermadec trenches (Pacific plate). Geophys. J. Int., 141(2), 479-484, doi: 10.1046/j.1365-246x.2000.00096.x.

Geman, S. and D. Geman (1993). Stochastic relaxation, Gibbs distributions and the Bayesian restoration of images. J. Appl. Stat., 20(5-6), 25-62, doi: 


\section{$10.1080 / 02664769300000058$}

Gohl, K., F. Nitsche and H. Miller (1997). Seismic and gravity data reveal Tertiary interplate subduction in the Bellingshausen Sea, southeast Pacific. Geology, 25(4), 371-374, doi: 10.1130/00917613(1997)025<0371:SAGDRT>2.3.C0;2.

Hastings, W. K. (1970). Monte Carlo sampling methods using Markov chains and their applications. Biometrika, 57(1), 97-109, doi: 10.1093/biomet/57.1.97.

Hayes, G. P., D. J. Wald and R. L. Johnson (2012). Slab1.0: A three-dimensional model of global subduction zone geometries. J. Geophys. Res.: Solid Earth, 117(B1), B01302, doi: 10.1029/2011JB008524.

Hjelt, S.-E. (1974). The gravity anomaly of a dipping prism. Geoexploration, 12(1), 29-39, doi: 10.1016/0016-7142(74)90004-0.

Ingber, L. (1996). Adaptive simulated annealing (ASA): Lessons learned. Control Cybern., 25(1), 33-54.

Kannan, D and V. Lakshmikantham (2002). Handbook of stochastic analysis and applications. Marcel Dekker Inc., New York.

Lallemand, S. E., J. Malavieille and S. Calassou (1992). Effects of oceanic ridge subduction on accretionary wedges: Experimental modeling and marine observations. Tectonics, 11(6), 1301-1313, doi: 10.1029/92TC00637.

Laske, G., G. Masters, Z. Ma and M. Pasyanos (2013). Update on CRUST1.0 - A 1-degree global model of Earth's crust. Geophys. Res. Abstract, 15, EGU2013-2658.

Li, Y. and D. W. Oldenburg (1998). 3-D inversion of gravity data. Geophysics, 63(1), 109-119, doi: 10.1190/1.1444302.

Mansi, A. H., M. Capponi and D. Sampietro (2018). Downward continuation of airborne gravity data by means of the change of boundary approach. Pure Appl. Geophys., 175(3), 977-988, doi: 10.1007/s00024-017-1717-5.

Mitronovas, W. and B. L. Isacks (1971). Seismic velocity anomalies in the upper mantle beneath the TongaKermadec island arc. J. Geophys. Res., 76(29), 7154-7180, doi: 10.1029/JB076i029p07154.

Mitronovas, W., B. Isacks and L. Seeber (1969). Earthquake locations and seismic wave propagation in the upper $250 \mathrm{~km}$ of the Tonga island arc. Bull. Seism. Soc. Am., 59(3), 1115-1135.

Nothard, S., J. Haines, J. Jackson and B. Holt (1996). Distributed deformation in the subducting lithosphere at Tonga. Geophys. J. Int., 127(2), 328-338, doi: 1111/j.1365-246X.1996.tb04723.x.
Oliver, J. and B. Isacks (1967). Deep earthquake zones, anomalous structures the upper mantle, and the lithosphere. J. Geophys. Res., 72(16), 4259-4275, doi: 10.1029/JZ072i016p04259.

Panet, I., G. Pajot-Métivier, M. Greff-Lefftz, L. Métivier, M. Diament and M. Mandea (2014). Mapping the mass distribution of Earth's mantle using satellite-derived gravity gradients. Nat. Geosci., 7, 131-135, doi: 10.1038/ngeo2063.

Reguzzoni, M. (2004). G0CE: the space-wise approach to gravity field determination by satellite gradiometry. PhD Thesis, Politecnico di Milano, Italy.

Reguzzoni, M., L. Rossi, M. Baldoncini, I. Callegari, P. Poli, D. Sampietro, V. Strati, F. Mantovani, et al. (2019). GIGJ: A crustal gravity model of the Guangdong Province for predicting the geoneutrino signal at the JUNO experiment. J. Geophys. Res.: Solid Earth, 124(4), 4231-4249, doi: 10.1029/2018JB016681.

Reguzzoni, M. and D. Sampietro (2015). GEMMA: an Earth crustal model based on GOCE satellite data. Int. J. Appl. Earth Obs., 35(Part A), 31-43, doi: 10.1016/j.jag.2014.04.002.

Reguzzoni, M., D. Sampietro and F. Sansò (2013). Global Moho from the combination of the CRUST2.0 model and GOCE data. Geophys. J. Int., 195(1), 222-237, doi: 10.1093/gji/ggt247.

Rossi, L., M. Reguzzoni, D. Sampietro and F. Sansò (2015). Integrating Geological Prior Information into the Inverse Gravimetric Problem: The Bayesian Approach. In: N. Sneeuw, P. Novák, M. Crespi and F. Sansò, VIII Hotine-Marussi Symposium on Mathematical Geodesy. IAG Symposia, 142, 317-324. Springer, Cham, doi: 10.1007/1345_2015_57.

Rummel, R., W. Yi and C. Stummer (2011). GOCE gravitational gradiometry. J. Geodesy, 85(11), 777-790, doi: 10.1007/s00190-011-0500-0.

Sampietro, D. and F. Sansò (2012). Uniqueness theorems for inverse gravimetric problems. In $\mathrm{N}$. Sneeuw, P. Novàk, M. Crespi and F. Sansò, VII Hotine-Marussi Symposium on Mathematical Geodesy, IAG Symposia, 137, 111-115, Springer, Berlin, Heidelberg, doi: 10.1007/978-3-64222078-4_17.

Sampietro, D., M. Capponi, A. H. Mansi, A. Gatti, P. Marchetti and F. Sansò (2017). Space-wise approach for airborne gravity data modelling. J. Geodesy, 91(5), 535-545, doi: 10.1007/s00190-016-0981-y.

Sampietro, D., M. Capponi, D. Triglione, A. H. Mansi, P. Marchetti and F. Sansò (2016). GTE: a new soft- 
ware for gravitational terrain effect computation: Theory and performances. Pure Appl. Geophys., 173(7), 2435-2453, doi: 10.1007/s00024-016$1265-4$

Sampietro, D., A. H. Mansi and M. Capponi (2018-a). A new tool for airborne gravimetry survey simulation. Geosciences, 8(8), 292, doi: 10.3390/geosciences8080292.

Sampietro, D., A. H. Mansi and M. Capponi (2018-b). Moho depth and crustal architecture beneath the Levant basin from global gravity field model. Geosciences, 8(6), 200, doi: 10.3390/geosciences8060200.

Sampietro, D., M. Reguzzoni and C. Braitenberg (2014). The GOCE estimated Moho beneath the Tibetan Plateau and Himalaya. In C. Rizos and P. Willis, Earth on the Edge: Science for a Sustainable Planet, IAG Symposia, 139, 391-397. Springer, Berlin, Heidelberg, doi: 10.1007/978-3-64237222-3_52.

Sansò, F. and M. G. Sideris (2013). Geoid Determination: Theory and Methods. Springer, Berlin, Heidelberg.

Sobh, M., J. Ebbing, A. H. Mansi and H.-J. Götze (2018a). Inverse and 3D forward gravity modelling for the estimation of the crustal thickness of Egypt. Tectonophysics, 752(5), 52-67, doi: 10.1016/j.tecto.2018.12.002.

Sobh, M., A. H. Mansi, S. Campbel and J. Ebbing (2018b). Regional gravity field model of Egypt based on the satellite and ground-based data. Pure Appl. Geophys., 176(2), 767-786, doi: 10.1007/s00024018-1982-y.

Sykes, L. R., B. L. Isacks and J. Oliver (1969). Spatial distribution of deep and shallow earthquakes of small magnitudes in the Fiji-Tonga region. Bull. Seism. Soc. Am., 59(3), 1093-1113.

Syracuse, E. and G. Abers (2006). Global compilation of variations in slab depth beneath arc volcanoes and implications. Geochem. Geophys. Geosyst., 7(5), Q05017, doi: 10.1029/2005GC001045.

Tondi, R., M. Gilardoni and M. Reguzzoni (2017). The combined inversion of seismological and GOCE gravity data: New insights into the current state of the Pacific lithosphere and upper mantle. Tectonophysics, 705, 101-115, doi: 10.1016/j.tecto.2017.03.013.

Tsokas, G. N., and R. O. Hansen (1997). Study of the crustal thickness and the subducting lithosphere in Greece from gravity data. J. Geophys. Res.: Solid Earth, 102(B9), 20585-20597, doi: 10.1029/97JB00730.
Van Der Hilst, R. (1995). Complex morphology of subducted lithosphere in the mantle beneath the Tonga trench. Nature, 374 (6518), 154-157, doi: $10.1038 / 374154 \mathrm{a} 0$.

Wackernagel, H. (2013). Multivariate geostatistics: An introduction with applications. Springer Science Et Business Media.

Wackernagel, H. (2014). Geostatistics. Wiley StatsRef: Statistics Reference Online.

Ye, Z., R. Tenzer, N. Sneeuw, L. Liu and F. Wild-Pfeiffer (2016). Generalized model for a Moho inversion from gravity and vertical gravity-gradient data. Geophys. J. Int., 207(1), 111-128, doi: 10.1093/gji/ggw251.

Zaki, A., A. H. Mansi, M. Rabah and G. El-Fiky (2018a). Validation of recently released GOCE-based satellite-only global geopotential models over the Red Sea using shipborne gravity data. Boll. Geofis. Teor. Appl., 59(3), 267-284, doi: 10.4430/bgta0242.

Zaki, A., A. H. Mansi, M. Selim, M. Rabah and G. ElFiky (2018-b). Comparison of satellite altimetric gravity and global geopotential models with shipborne gravity in the Red Sea. Mar. Geod., 41(3), 258-269, doi: 10.1080/01490419.2017.1414088.

"CORRESPONDING AUTHOR: Ahmed Hamdi MANSI, Civil Engineering Department, College of Engineering, Shaqra University, Dawadmi, Ar Riyadh, Saudi Arabia; email: ahmed.mansi@su.edu.sa (C) 2019 the Istituto Nazionale di Geofisica e Vulcanologia. All rights reserved 